Int. J. Electrochem. Sci., 13 (2018) 2219 - 2235

\title{
Comparison of the Inhibition Effect of Four Inhibitors on the Corrosion Behaviour of AM60 Magnesium Alloy
}

\author{
Dan Liu ${ }^{1,2}$, Yingwei Song ${ }^{1, *}$, Dayong Shan ${ }^{1}$, En-Hou Han ${ }^{1}$ \\ ${ }^{1}$ Key Laboratory of Nuclear Materials and Safety Assessment, Institute of Metal Research, Chinese \\ Academy of Sciences, Shenyang 110016, China \\ ${ }^{2}$ School of Materials Science and Engineering, University of Science and Technology of China, Hefei \\ 230026, China \\ *E-mail: ywsong@imr.ac.cn
}

doi: $10.20964 / 2018.03 .23$

Received: 3 November 2017 / Accepted: 5 January 2018 / Published: 5 February 2018

\begin{abstract}
The inhibition effect of four inhibitors of sodium citrate (SC), sodium dodecylbenzenesulphonate (SDBS), diammonium phosphate $\left(\left(\mathrm{NH}_{4}\right)_{2} \mathrm{HPO}_{4}\right)$ and sodium vanadate $\left(\mathrm{NaVO}_{3}\right)$ on the corrosion behaviour of AM60 magnesium alloy in $0.1 \mathrm{M}$ sodium chloride $(\mathrm{NaCl})$ solution was investigated by immersion and electrochemical tests, surface morphology and chemical composition analyses. The results show that AM60 suffers severe attack in $\mathrm{NaCl}$ solution in long-term immersion. When inhibitors are added, its corrosion resistance is improved. All these inhibitors can form a barrier to inhibit the corrosion process. Especially, the barrier becomes more protective after longer immersion. All the inhibitors except $\left(\mathrm{NH}_{4}\right)_{2} \mathrm{HPO}_{4}$ can prevent the localized corrosion of AM60. The inhibition efficiency of organic inhibitors is better than that of inorganic inhibitors. The most efficient inhibitor is SDBS with efficiency up to $93 \%$ measured by hydrogen evolution.
\end{abstract}

Keywords: Magnesium alloys; Inhibitors; Inhibition efficiency; Corrosion resistance; Product films

\section{FULL TEXT}

(C) 2018 The Authors. Published by ESG (www.electrochemsci.org). This article is an open access article distributed under the terms and conditions of the Creative Commons Attribution license (http://creativecommons.org/licenses/by/4.0/). 